\title{
Extracellular hemin crisis triggers acute chest syndrome in sickle mice
}

\author{
Samit Ghosh, Olufolake Adetoro Adisa, Prasanthi Chappa, Fang Tan, \\ Kesmic Ann Jackson, David Robert Archer, and Solomon Fiifi Ofori-Acquah
}

Aflac Cancer and Blood Disorders Center, Department of Pediatrics, Emory University School of Medicine, Atlanta, Georgia, USA.

\begin{abstract}
The prevention and treatment of acute chest syndrome (ACS) is a major clinical concern in sickle cell disease (SCD). However, the mechanism underlying the pathogenesis of ACS remains elusive. We tested the hypothesis that the hemolysis byproduct hemin elicits events that induce ACS. Infusion of a low dose of hemin caused acute intravascular hemolysis and autoamplification of extracellular hemin in transgenic sickle mice, but not in sickle-trait littermates. The sickle mice developed multiple symptoms typical of ACS and succumbed rapidly. Pharmacologic inhibition of TLR4 and hemopexin replacement therapy prior to hemin infusion protected sickle mice from developing ACS. Replication of the ACS-like phenotype in nonsickle mice revealed that the mechanism of lung injury due to extracellular hemin is independent of SCD. Using genetic and bone marrow chimeric tools, we confirmed that TLR4 expressed in nonhematopoietic vascular tissues mediated this lethal type of acute lung injury. Respiratory failure was averted after the onset of ACS-like symptoms in sickle mice by treating them with recombinant hemopexin. Our results reveal a mechanism that helps to explain the pathogenesis of ACS, and we provide proof of principle for therapeutic strategies to prevent and treat this condition in mice.
\end{abstract}

\section{Introduction}

Sickle cell disease (SCD) affects an estimated 100,000 people in the United States and millions more around the world (1). Acute chest syndrome (ACS) is the second most common reason for hospital admission of SCD patients (2) and the leading cause of referral to intensive care units (3), and it is associated with a high mortality rate (4). ACS diagnosis is associated with decreasing hemoglobin $(\mathrm{Hb})$ concentration, hypoxemia, and multilobular lung infiltration (5). Lung injury in ACS is characterized predominantly by edema formation (6). Because the molecular and cellular mechanisms involved are unknown, management of this condition is entirely supportive.

Antecedent clinical events associated with ACS development include intravascular sickling (7), fat emboli, hypoxia (8), microvascular in situ thrombosis (8), infection (9), and acute painful vaso-occlusive crisis (VOC) (5). There have been attempts to model ACS in transgenic sickle mice using endotoxin (10), severe hypoxia (11), progressive hypoxia (12), and hypoxia/reoxygenation $(13,14)$. To date, no preclinical ACS model has been successfully established, which poses a major barrier to progress in the management of this condition. In addition, ACS diagnosis is a major challenge, as evidenced by the failure to find a specific etiological factor in nearly $50 \%$ of cases in the study by the National Acute Chest Syndrome Study Group (5). Regardless of the initial symptoms, however, most SCD patients experience acute hemolysis before showing evidence of oxygen desaturation $(8,15,16)$. Thus, danger-associated molecular pattern molecules derived from the lysis of erythrocytes may ultimately contribute to lung injury in ACS. Among the potential candidates, hemin (the oxidized prosthetic moiety of $\mathrm{Hb}$ ) is prototypical. It is a potent inflammatory agonist (17) and activator of TLR4 (18). Hemolysis inevitably results in the release of hemin into the extracellular space. This process is probably accelerated in SCD because of the enhanced auto-oxidation of

Conflict of interest: The authors have declared that no conflict of interest exists. Citation for this article: JClin Invest. 2013;123(11):4809-4820. doi:10.1172/JCI64578. sickle-cell oxyhemoglobin (19-22) and the presence of free hemin at high concentrations $(\sim 1 \mu \mathrm{M})$ inside sickle erythrocytes (23).

In the Cooperative Study of Sickle Cell Disease, severe acute hemolysis was the only predictor of sudden death due to ACS (15). A polymorphism that increases the expression of heme oxygenase-1 (HO-1), the rate-limiting hemin degradation enzyme, is associated with lower rates of hospitalization for ACS (24). These data, together with the observation that oxidative stress (a promoter of hemin release) increases markedly in patients with ACS (25), enhances the logic that hemin may play a central role in the pathogenesis of this condition. Here, we investigated the idea that extracellular hemin may trigger events that recapitulate the inflammation associated with ACS in clinically relevant transgenic mouse models of SCD.

\section{Results}

Extracellular hemin elevation causes a lethal hemolytic crisis in sickle mice. To mimic acute extracellular hemin release, transgenic Townes sickle mice (referred to herein as SS mice; see Methods) and control sickletrait (AS) and wild-type human $\mathrm{Hb}$ (AA) mice were infused with a relatively low dose of purified hemin $(35 \mu \mathrm{mol} / \mathrm{kg})$. No adverse effects were seen in the control mice, but a majority of SS mice developed labored breathing and died within 2 hours (Figure 1A). We confirmed these acute adverse effects in a second murine model of SCD (Berkeley sickle mice; see Methods) and showed that the lethality rate was dependent on the dose of hemin (Figure 1B). A previous study had shown that $40 \mu \mathrm{mol} / \mathrm{kg}$ hemin given i.p. did not cause any fatalities in the Berkeley sickle mouse (26). A higher dose $(70 \mu \mathrm{mol} / \mathrm{kg})$ given i.v. had no adverse effects in wild-type mice $(17,27)$; moreover, the SS mouse deaths occurred 24 hours before hepatic failure onset, due to hemin overload in septic mice (28). Thus, our results in the SS mice revealed an unusual effect of extracellular hemin that had not previously been described.

Plasma hemopexin (Hx) levels decreased sharply in all animals, coincident with nearly $50 \%$ clearance of the hemin bolus within 

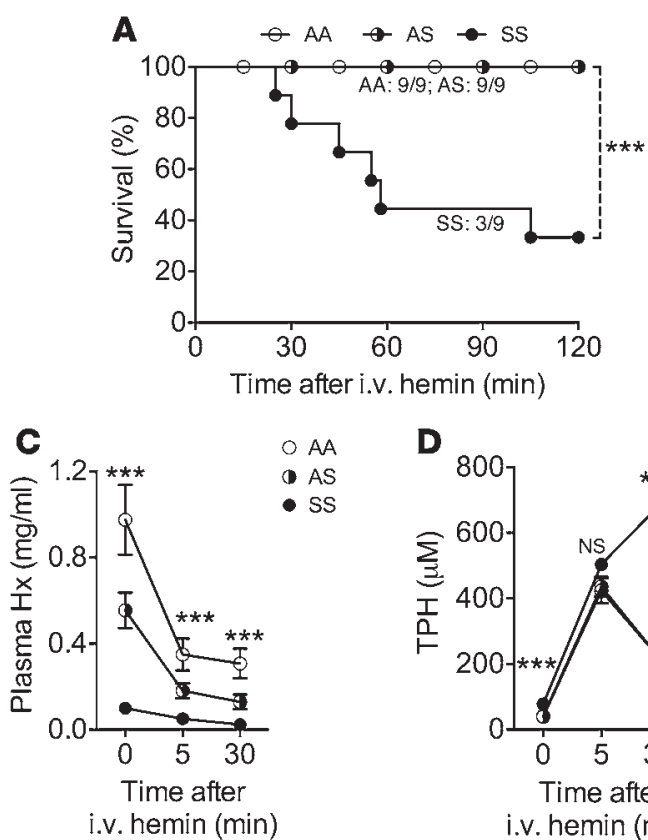

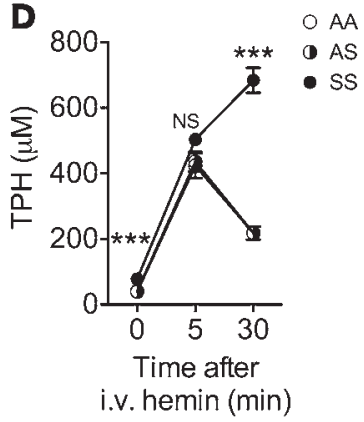

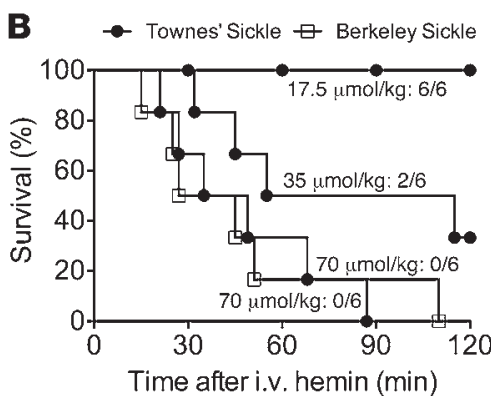

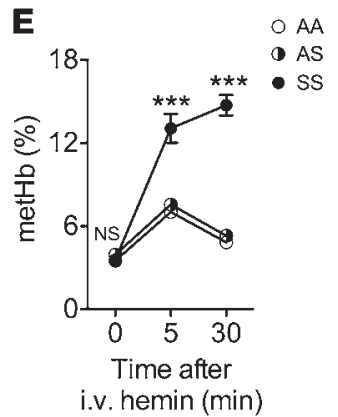

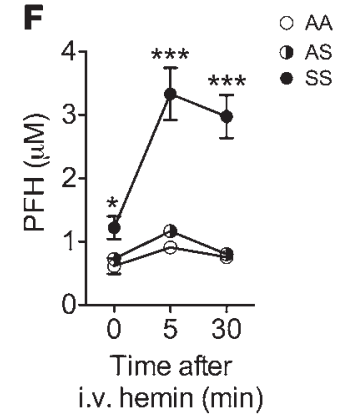

\section{Figure 1}

Sudden death associated with EHC. (A) Relatively low dose of hemin $(35 \mu \mathrm{mol} / \mathrm{kg})$ caused sudden death in SS mice, but not in control AS and AA mice $(n=9)$. (B) Lethality associated with hemin in Townes sickle mice was dose dependent $(n=6) .100 \%$ lethality of sickle mice challenged with $70 \mu \mathrm{mol} / \mathrm{kg}$ hemin was confirmed using the Berkeley sickle mouse model $(n=6)$. (C-F) Characterization of EHC associated with sudden death in SS mice. $n=9$ (SS); 6 (AA and AS). (C) Plasma Hx was significantly lower in SS mice at baseline $(t=0)$ and declined sharply in all 3 groups after hemin challenge. (D) SS mice had markedly higher TPH than AS and AA mice at baseline. TPH initially increased to the same level in all 3 groups. Hemin clearance by AA and AS mice and amplification by SS mice explains the significantly different values at 30 minutes. (E) metHb and (F) PFH in SS and control mice at baseline and 5 and 30 minutes after hemin challenge. ${ }^{*} P<0.05,{ }^{* *} P<0.001$.

30 minutes in control animals (Figure 1, C and D). Unexpectedly, total plasma hemin (TPH) increased in SS mice approximately $200 \mu \mathrm{M}$ beyond the amount of hemin infused, concomitant with a sharp decrease in total $\mathrm{Hb}$ (mean, $1.4 \mathrm{~g} / \mathrm{dl}$; Supplemental Figure 1; supplemental material available online with this article; doi:10.1172/JCI64578DS1). Whole blood co-oximetry revealed a 4-fold increase in percent methemoglobin (metHb; Figure 1E), indicative of a robust and sustained increase in oxidant stress exclusively in SS mice. In agreement with these changes, the concentration of plasma free hemin (PFH) increased sharply and remained elevated in SS mice (Figure 1F). These results demonstrated a phenomenon of hemin autoamplification that had not been described before, which we named extracellular hemin crisis (EHC).

EHC is a prodrome to lethal acute lung injury in SS mice. Respiratory dysfunction in ACS patients is investigated routinely using pulse oximetry $(16,29)$. We adopted this approach to monitor SS mice using a validated mouse pulse oximeter $(30,31)$. Baseline levels of pulse oximetry oxygen saturation $\left(\mathrm{SpO}_{2}\right)$ were not different in $\mathrm{SS}$ and control mice, as reported previously (32). After challenge with $70 \mu \mathrm{mol} / \mathrm{kg}$ hemin, $\mathrm{SpO}_{2}$ in SS mice decreased progressively, reaching approximately $85 \%$ for the majority within 30 minutes (Figure $2 \mathrm{~A}$ ). In contrast, $\mathrm{SpO}_{2}$ for the control animals remained unchanged throughout the experiment. The breath rate reflected the changes - or lack thereof - in $\mathrm{SpO}_{2}$ (Figure 2, $\mathrm{A}$ and B). To confirm hypoxemia, we measured arterial blood gases. This experiment required full anesthetization of mice with ketamine and xylazine, which causes mild respiratory depression in rodents $(33,34)$. The baseline levels of arterial oxygen tension $\left(\mathrm{PaO}_{2}\right)$ and $\mathrm{pH}$ were closer to normal in AA mice, but reduced in SS mice (Table 1). Arterial oxygen saturation $\left(\mathrm{SO}_{2}\right)$ for the SS mice matched previously reported values (35). Blood samples obtained 20 minutes after injection with $70 \mu \mathrm{mol} / \mathrm{kg}$ hemin revealed severe hypoxemia and worsening hypercapnia and acidosis - all hallmarks of acute lung injury (ALI) - in SS mice; no significant changes occurred in AA mice (Figure $2 \mathrm{C}$ and Table 1 ). $\mathrm{SO}_{2}$ values obtained using the 2 methods correlated with high significance $(r=0.97, P<0.0001$, $n=22$; data not shown). Lungs of SS mice that succumbed to hemin revealed vascular congestion, edema, alveolar wall thickening, and hemorrhage (Figure 2, D-F).

Components of EHC associated with lethal ALI in SS mice. To determine whether intravascular hemolysis per se causes ALI in SS mice, we studied the phenylhydrazine hemolysis model. Raised plasma $\mathrm{Hb}$ levels confirmed acute intravascular hemolysis in mice challenged with phenylhydrazine (Supplemental Figure 2A). However, hemolysis was relatively modest, was not specific to the SS mice, and did not significantly raise PFH or exhaust plasma $\mathrm{Hx}$ levels (Supplemental Figure 2, B and C). Importantly, SS mice that experienced phenylhydrazine-induced intravascular hemolysis did not develop ALI (Figure 2F). To further define the hemolytic components involved in the hemin ALI model, a random cohort of SS mice $(n=14)$ was challenged with $35 \mu \mathrm{mol} / \mathrm{kg}$ hemin. As expected, approximately $30 \%$ of these animals survived, while the majority developed severe respiratory symptoms and died within 2 hours (data not shown). Analysis of blood samples taken 5 minutes after hemin challenge showed no difference in the acute levels of met $\mathrm{Hb}$ percentage, plasma $\mathrm{Hb}$, or TPH in association with these 2 dispa- 

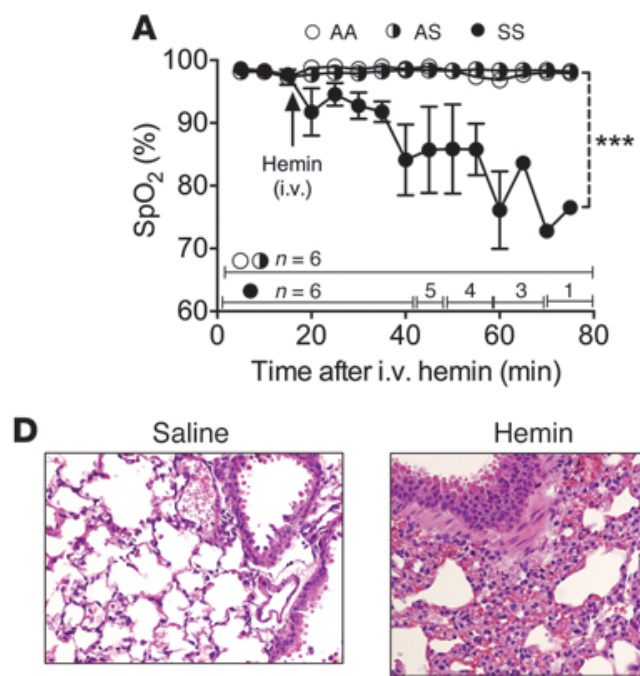

Control

E

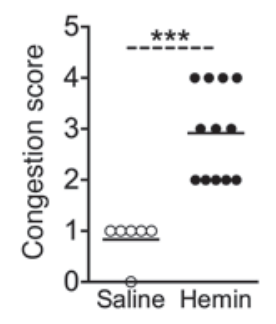

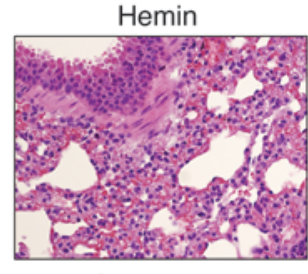

Congestion

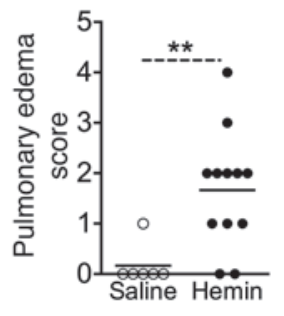

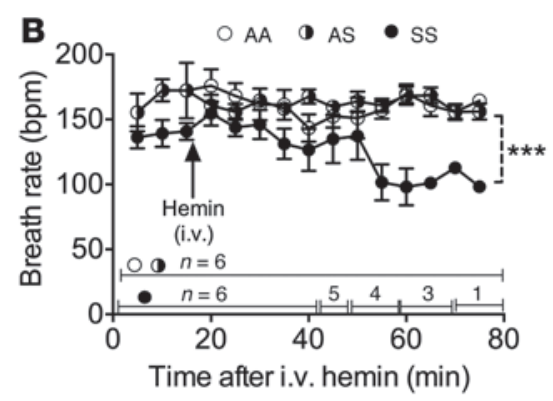

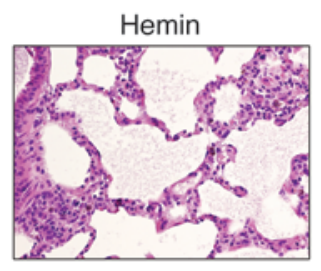

Edema

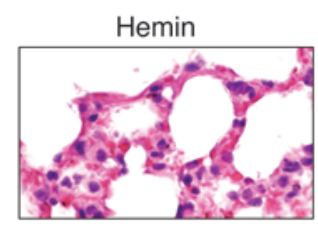

Alveolar wall thickening
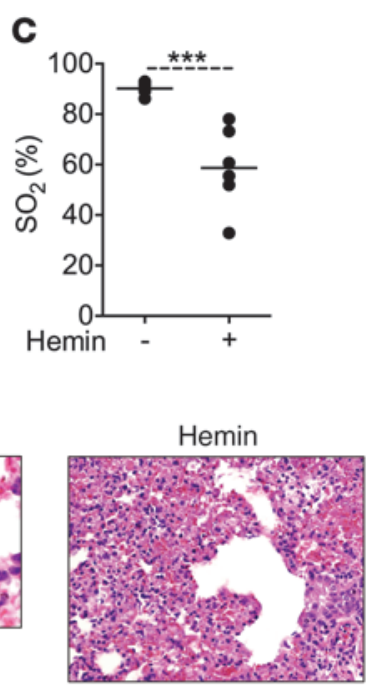

Hemorrhage

F
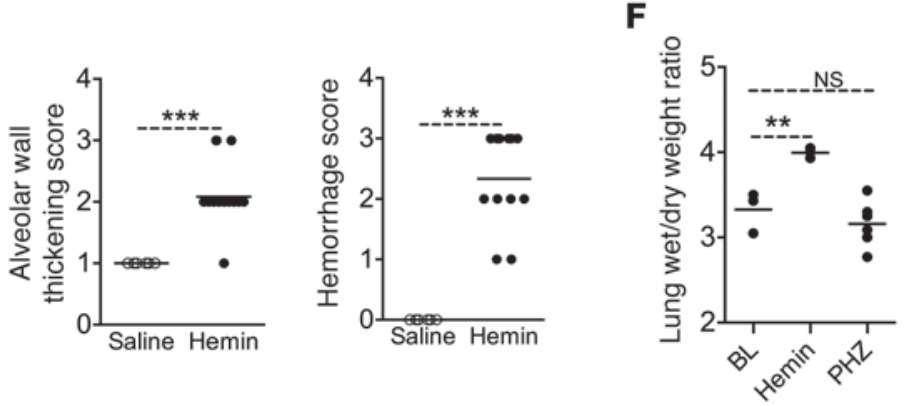

\section{Figure 2}

$\mathrm{SS}$ mice with EHC develop ALI. (A) $\mathrm{SpO}_{2}$ and (B) breath rate, as determined by pulse oximetry, in SS mice and control animals challenged with hemin $(n=6)$. The number of surviving animals at each time point is indicated. (C) $\mathrm{SO}_{2}$, measured using the VitalPath blood gas analyzer, in samples obtained from the left ventricle of anesthetized SS mice at baseline and in another cohort of SS mice 20 minutes after hemin challenge ( $n=6$ per group). (D) Representative H\&E-stained lung sections of SS mice challenged with saline or hemin. Original magnification, $\times 200$ (alveolar wall thickening), $\times 100$ (all other panels). (E) Semiquantitative histological scoring of lung injury in SS mice in D. (F) Assessment of lung injury, using gravimetric analysis, in SS mice at baseline (BL) and after induction of intravascular hemolysis using hemin and phenylhydrazine (PHZ). ${ }^{\star *} P<0.01,{ }^{* \star *} P<0.001$.

rate outcomes (Figure 3, A-C). However, compared with the animals that survived, those that died had significantly higher acute $\mathrm{PFH}$, consistent with the approximately 2-fold lower mean baseline plasma Hx (Figure 3, D and E). A significantly higher lung wet/dry weight ratio confirmed that the nonsurviving SS mice had severe ALI (Figure 3F). Collectively, these results suggested that PFH, not plasma $\mathrm{Hb}$ or metHb, was the major ALI trigger in this model.

Low plasma $H x$ is a risk factor for hemin-induced lethal ALI in SS mice. To test whether Hx plays a protective role in this new model of ALI, 3 groups of SS mice (defined by baseline $\mathrm{Hx}$ level) were challenged with $35 \mu \mathrm{mol} / \mathrm{kg}$ hemin. All animals in the low-Hx group $(<0.1 \mathrm{mg} / \mathrm{ml}$ or $<1.67 \mu \mathrm{M} ; n=7)$ developed respiratory symptoms and died within 2 hours, and $50 \%$ of the high-Hx group $(>0.25 \mathrm{mg} / \mathrm{ml}$ or $>4.16 \mu \mathrm{M} ; n=10)$ survived, while the medium-Hx group $(0.1-0.25 \mathrm{mg} / \mathrm{ml}$ or $1.67-4.16 \mu \mathrm{M} ; n=9)$ had an intermediate prognosis (Figure 4A). Next, we assessed the prophylactic potential of recombinant human $\mathrm{Hx}(\mathrm{rhHx})$, and to exclude the potential contribution of LPS contamination of hemin to ALI. SS mice were randomized to receive $1 \mathrm{mg} \mathrm{rhHx}, 50 \mu \mathrm{g}$ polymyxin $\mathrm{B}, 1 \mathrm{mg}$ human IgG, or $200 \mu \mathrm{l} \mathrm{Hx}$ carrier vehicle, and then challenged with
$70 \mu \mathrm{mol} / \mathrm{kg}$ hemin. Mice pretreated with $\mathrm{Hx}$ did not develop ALI and remained alive, while all others developed severe respiratory symptoms and succumbed within 2 hours (Figure 4B). These results unambiguously identified $\mathrm{PFH}$ as the dominant factor responsible for lethal ALI in SS mice. In another experiment, a cohort of SS mice was challenged with hypoxia ( $8 \%$ oxygen) for 3 hours, followed by reoxygenation for 4 hours. None of these mice succumbed, consistent with the lack of acute adverse outcome in previous studies using similar hypoxia/reoxygenation protocols (data not shown). $\mathrm{SpO}_{2}$ and breath rate did not change from baseline at the end of reoxygenation, and histology showed no evidence of lung injury (Figure 4, C-E). Interestingly, hypoxia/reoxygenation decreased plasma $\mathrm{Hb}$, while $\mathrm{PFH}$ remained unchanged, in SS mice (Supplemental Figure 3A and Figure 4F). These data were corroborated by increased plasma concentrations of $\mathrm{Hx}$ and haptoglobin in the same animals (Figure 4G and Supplemental Figure 3B).

Extracellular and intracellular hemin toxicities are organ specific. Excess circulating hemin has previously been implicated in the development of hepatic failure (28). We reasoned that the mechanism of hepatic and lung toxicity described herein is unique. To 


\section{Table 1}

Arterial blood gases in SS and AA mice at baseline and 20 minutes after i.v. hemin

\begin{tabular}{lcccc} 
& \multicolumn{2}{c}{ SS $(\boldsymbol{n}=\mathbf{6})$} & \multicolumn{2}{c}{ AA $(\boldsymbol{n}=\mathbf{5})$} \\
& Baseline & Hemin & Baseline & Hemin \\
$\mathrm{PaO}_{2}(\mathrm{~mm} / \mathrm{Hg})$ & $67.65 \pm 1.56$ & $40.23 \pm 3.84^{\mathrm{A}}$ & $87.98 \pm 5.38$ & $74.78 \pm 10.4$ \\
$\mathrm{SO}_{2}(\%)$ & $90.2 \pm 0.99$ & $58.72 \pm 6.6^{\mathrm{B}}$ & $94.94 \pm 1.3$ & $89.14 \pm 2.2$ \\
$\mathrm{PaCO}_{2}(\mathrm{~mm} / \mathrm{Hg})$ & $46.73 \pm 3.02$ & $56.08 \pm 3.64$ & $46.36 \pm 2.26$ & $43.58 \pm 5.22$ \\
$\mathrm{pH}$ & $7.29 \pm 0.2$ & $7.21 \pm 0.0$ & $7.37 \pm 0.11$ & $7.27 \pm 0.03$
\end{tabular}

Values are mean \pm SEM. ${ }^{A} P<0.0001, B P=0.0008$ vs. baseline.
NCEH (Figure 5E). These results showed that excess circulating hemin caused at least 2 spatiotemporal pathologies defined by the extra- and intracellular compartmentalization of hemin.

The TLR4 antagonist TAK-242 protects SS mice from hemin-induced ALI. To define the primary mediator of the acute inflammatory response to $\mathrm{PFH}$, we focused on TLR4, a known hemin receptor (18). TAK-242 binds to Cys 747 of the intracellular domain of TLR4 and inhibits downstream signaling (36). A cohort of SS mice was given i.v. TAK-242 or its intralipid vehicle, and then EHC was induced with $35 \mu \mathrm{mol} / \mathrm{kg}$ hemin. TAK-242 and vehicle did not alter hemin scavenging: lung function remained normal in the majority of SS test this idea, groups of SS mice were injected with $70 \mu \mathrm{mol} / \mathrm{kg}$ hemin to induce EHC or with $25 \mu \mathrm{mol} / \mathrm{kg}$ to create a noncritical elevation in extracellular hemin (NCEH). EHC caused severe hypoxemia and $100 \%$ lethality within 2 hours, while NCEH was characterized by normal $\mathrm{SpO}_{2}$ and $45 \%$ lethality $12-72$ hours later (Figure 5, A and B). SS mice at baseline showed raised plasma concentrations of alanine transaminase (ALT; SS, $150.5 \pm 26.5 \mathrm{IU} / \mathrm{l}$; AS, $57.7 \pm 13.2 \mathrm{IU} / 1$; AA, $29.5 \pm 8.3 \mathrm{IU} / 1 ; n=6 ; P=0.0006)$ and aspartate transaminase (AST; SS, $321.6 \pm 39.4 \mathrm{IU} / \mathrm{l}$; AS, $185.5 \pm 31.1 \mathrm{IU} / 1 ; \mathrm{AA}, 154.7 \pm 32.3 \mathrm{IU} / 1 ; n=6 ; P=0.0086)$, indicative of underlying liver disease. ALT and AST levels in SS mice with EHC remained unchanged at the median time of death. Meanwhile, ALT and AST rose 3.0- and 4.3-fold, respectively, 24 hours later in NCEH animals (Figure 5, C and D), which implicated hepatic failure in the death of these animals (Figure 5B). Histological analysis of H\&E-stained sections confirmed the organ-specific damage: iron was more abundant and diffusely distributed in the cytoplasm in the hepatocytes of SS mice with mice pretreated with $5 \mathrm{mg} / \mathrm{kg}$ TAK-242, whereas those pretreated with vehicle developed hypoxemia (Figure 6, A and B). $72 \%$ of SS mice given $5 \mathrm{mg} / \mathrm{kg}$ TAK-242 were protected, compared with $57 \%$ and $26 \%$ given $3 \mathrm{mg} / \mathrm{kg}$ TAK-242 and vehicle, respectively (Figure 6C). The prophylactic effect of TAK-242 against ALI was confirmed by histology (Figure 6, D and E).

Extracellular hemin causes lethal ALI in wild-type mice, but not TLR4null mice. To confirm the involvement of TLR4 in this new model of ALI, we studied mutant mouse strain B6.B10ScN-Tlr4lps-del/JthJ (referred to herein as B6TLR4-/-), with a small deletion in the mouse Tlr4 gene, and its wild-type control (B6TLR4 $\left.4^{+/}\right)$(37). A relatively high dose of hemin $(210 \mu \mathrm{mol} / \mathrm{kg})$ was required to raise $\mathrm{PFH}$ in these mice to comparable levels in the SS mice given $35 \mu \mathrm{mol} / \mathrm{kg}$. Whereas B6TLR $4^{+/+}$mice developed lethal ALI, B6TLR4-/mice remained asymptomatic (Figure 7, A-E). The high $210-\mu \mathrm{mol} / \mathrm{kg}$ hemin dose used in this experiment was also lethal in AS and AA mice (Supplemental Figure 4A). These results confirmed that the basic mechanism responsible for the lung injury in our model
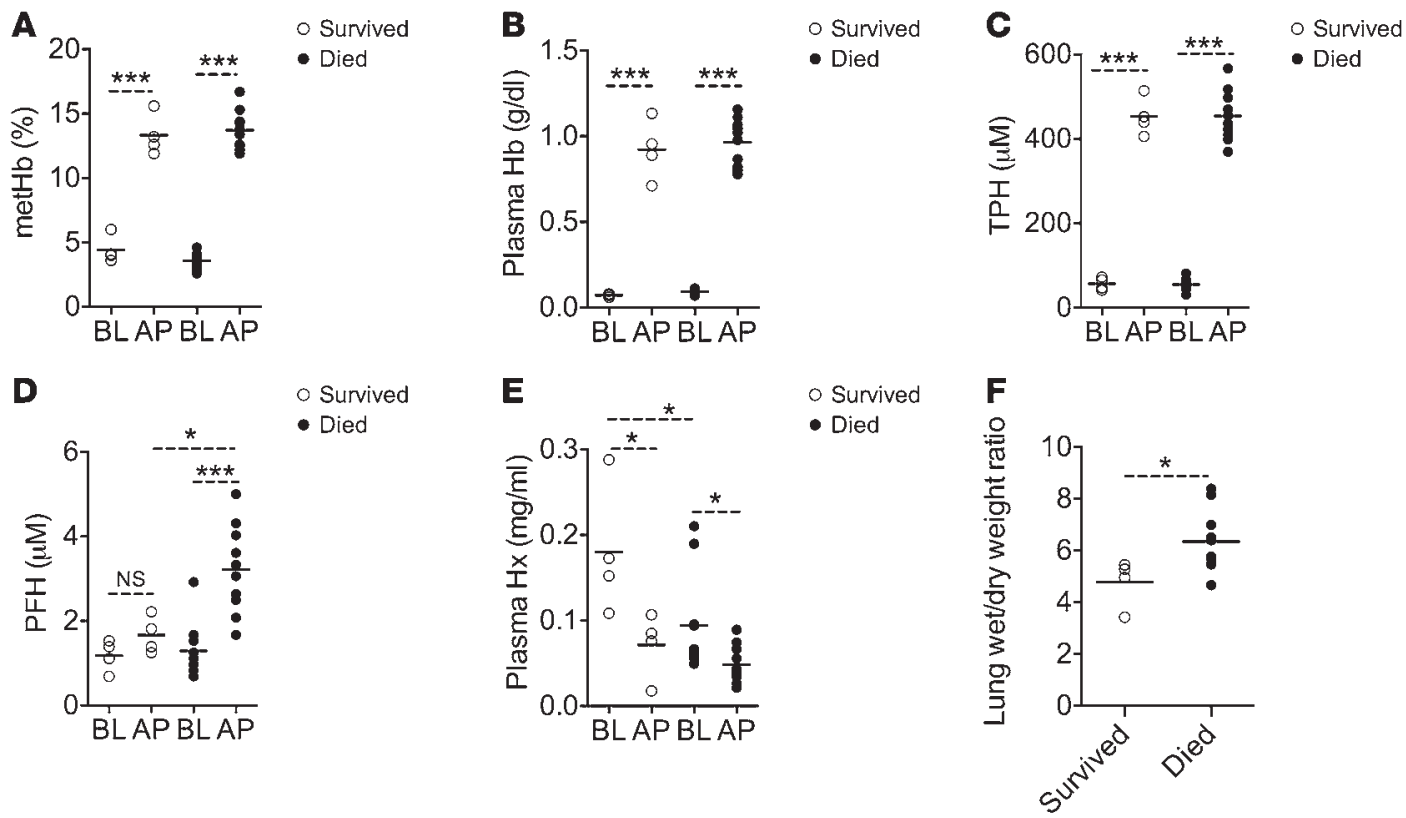

\section{Figure 3}

Components of EHC associated with lethal ALI. (A-E) Baseline and acute phase (AP) hematological parameters in SS mice that survived or succumbed to hemin. Samples for baseline value measurements were collected approximately 5 days before the experiment, and acute phase values were determined in samples collected 5 minutes after i.v. challenge with $35 \mu \mathrm{mol} / \mathrm{kg}$ hemin. (A) metHb. (B) Plasma Hb. (C) TPH. (D) PFH. (E) Plasma Hx. (F) The higher lung wet/dry weight ratio in SS mice with EHC that died is indicative of lung edema development. ${ }^{\star} P<0.05$, ${ }^{* * *} P<0.001$. 

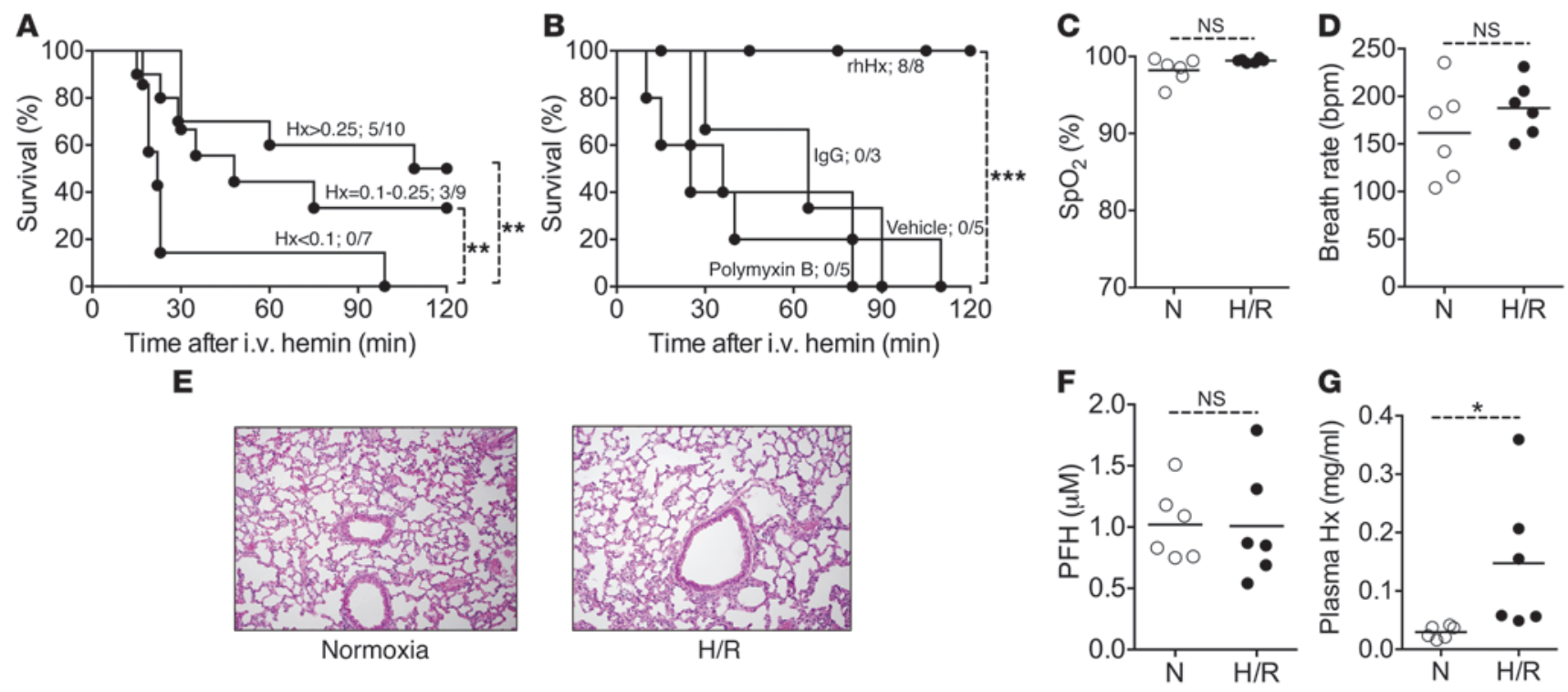

\section{Figure 4}

$\mathrm{Hx}$ is a prognostic factor in hemin-induced ALI. (A) Survival rate of $26 \mathrm{SS}$ mice with different baseline plasma Hx levels challenged with $35 \mu \mathrm{mol} / \mathrm{kg}$ hemin. (B) Survival rate of SS mice given $\mathrm{rhHx}(n=8)$, IgG $(n=3)$, carrier vehicle for the $\mathrm{Hx}(n=5)$, and polymyxin $\mathrm{B}(n=5)$ prior to challenge with $70 \mu \mathrm{mol} / \mathrm{kg}$ hemin. (C) $\mathrm{SpO}_{2}$ and (D) breath rate measured at normoxia (N) and after hypoxia/reoxygenation (H/R). (E) Representative H\&Estained lung sections of SS mice at normoxia and after hypoxia/reoxygenation. Original magnification, $\times 100$. (F) PFH and (G) plasma Hx during normoxia and after hypoxia/reoxygenation. ${ }^{*} P<0.05$, ${ }^{* \star} P<0.01,{ }^{\star * *} P<0.001$.

is independent of SCD. Previous studies have shown that other porphyrins do not activate TLR4 (18). In agreement with those findings, sodium protoporphyrin IX (Na-PPIX) and iron mesoporphyrin [Fe(III)MPIX] had no adverse effects in $\mathrm{B} 6 \mathrm{TLR} 4^{+/+}$mice (Supplemental Figure 4B). To further confirm the involvement of TLR4, we performed experiments in the $\mathrm{C} 3 \mathrm{H} / \mathrm{HeJ}$ mouse. This strain was also protected from the severe respiratory symptoms and sudden lethality associated with $\mathrm{PFH}$, whereas its wild-type control $(\mathrm{C} 3 \mathrm{H} / \mathrm{HeOuJ})$ was not (Supplemental Figure 5). However, all $\mathrm{C} 3 \mathrm{H} / \mathrm{HeJ}$ mice died within 2 days, with evidence of severe hepatic failure (Supplemental Figure 6, A-D). Thus, TLR4 mediated the lethal ALI induced by PFH, while the hepatic toxicity involving intracellular hemin was TLR4 independent.

The TLR4-mediating lethal ALI in SS mice resides in the vessel wall. To identify the key cell population involved in this new ALI model involving hemin, we used bone marrow chimeras to isolate the effects on hematopoietic (e.g., neutrophil) or resident nonhematopoietic (e.g., endothelium) components. Bone marrow from SS mice was transplanted into B6TLR $4^{+/+}$and B6TLR $4^{-/-}$mice to generate sickle hematopoietic and nonhematopoietic chimeras, respectively (referred to herein as SSTLR4+/+ and SSNH/TLR4-/-). The chimeras acquired a hematological phenotype similar to that of wild-type SS (SS ${ }^{\mathrm{WT}}$ ) mice 8 weeks after transplantation (Supplemental Table 1). EHC was successfully induced in both chimeras (Table 2). Subsequently, SS ${ }^{\text {TLR4+/+ }}$ chimeras developed labored breathing, became hypoxemic, and suffered a high rate of lethality, whereas SSNH/TLR4-/- chimeras remained asymptomatic (Figure 8, $\mathrm{A}-\mathrm{C})$. These findings were corroborated by histology and gravimetric analysis (Figure 8, D-F).

$H x$ and TAK-242 treatment prevents respiratory failure in SS mice. We examined the feasibility of hemin sequestration and TLR4 blockade as a therapeutic strategy to treat the acute effects of excess extracellular hemin. Random cohorts of SS mice were treated with rhHx and TAK-242 at the onset of hemolytic crisis, immediately after challenge with $35 \mu \mathrm{mol} / \mathrm{kg}$ hemin. None of the Hx-treated animals developed respiratory symptoms, and they all survived; $>70 \%$ of mice given $7.5 \mathrm{mg} / \mathrm{kg}$ TAK-242 were also effectively treated. However, a lower $5-\mathrm{mg} / \mathrm{kg}$ TAK-242 dose, which was effective as prophylaxis in our earlier experiments, was not effective as a therapeutic in this experiment (Figure 9A). At 20 minutes after initiation of treatment, $\mathrm{SpO}_{2}$ was normal in all mice given $\mathrm{Hx}$, and in a majority 8 of 11 (73\%) given $7.5 \mathrm{mg} / \mathrm{kg}$ TAK-242. $\mathrm{SpO}_{2}$ values were $<95 \%$ in 3 of 11 (27\%) SS mice given TAK-242 and in 5 of 6 (83\%) untreated mice, none of which recovered (Figure 9B).

Analysis of blood samples collected 30 minutes after treatment showed that rhHx effectively cleared hemin from the mouse circulation (Figure 9C). As expected, TPH remained elevated in TAK-242treated mice (Figure 9C), since the mechanism of action of this drug is TLR4 blockade, not hemin sequestration. ALI, assessed by histology and lung wet/dry weight ratio, was consistent with our lung physiology and survival data (Figure 9, D-F). Finally, in a subset of SS mice, we initiated treatment when there was evidence of respiratory distress, as determined by significant reductions in $\mathrm{SpO}_{2}$. Treatment with rhHx reversed the decline in $\mathrm{SpO}_{2}$, followed by steady improvement in breath rate and normalization of lung function (Figure 9, G and H). TAK-242 did not rescue these SS mice, analogous to prior findings in a mouse endotoxin model when the drug was given after the disease process involving LPS was already well underway (38).

\section{Discussion}

We report a new mechanism of ALI involving extracellular hemin that may have important ramifications for the diagnosis, pre- 

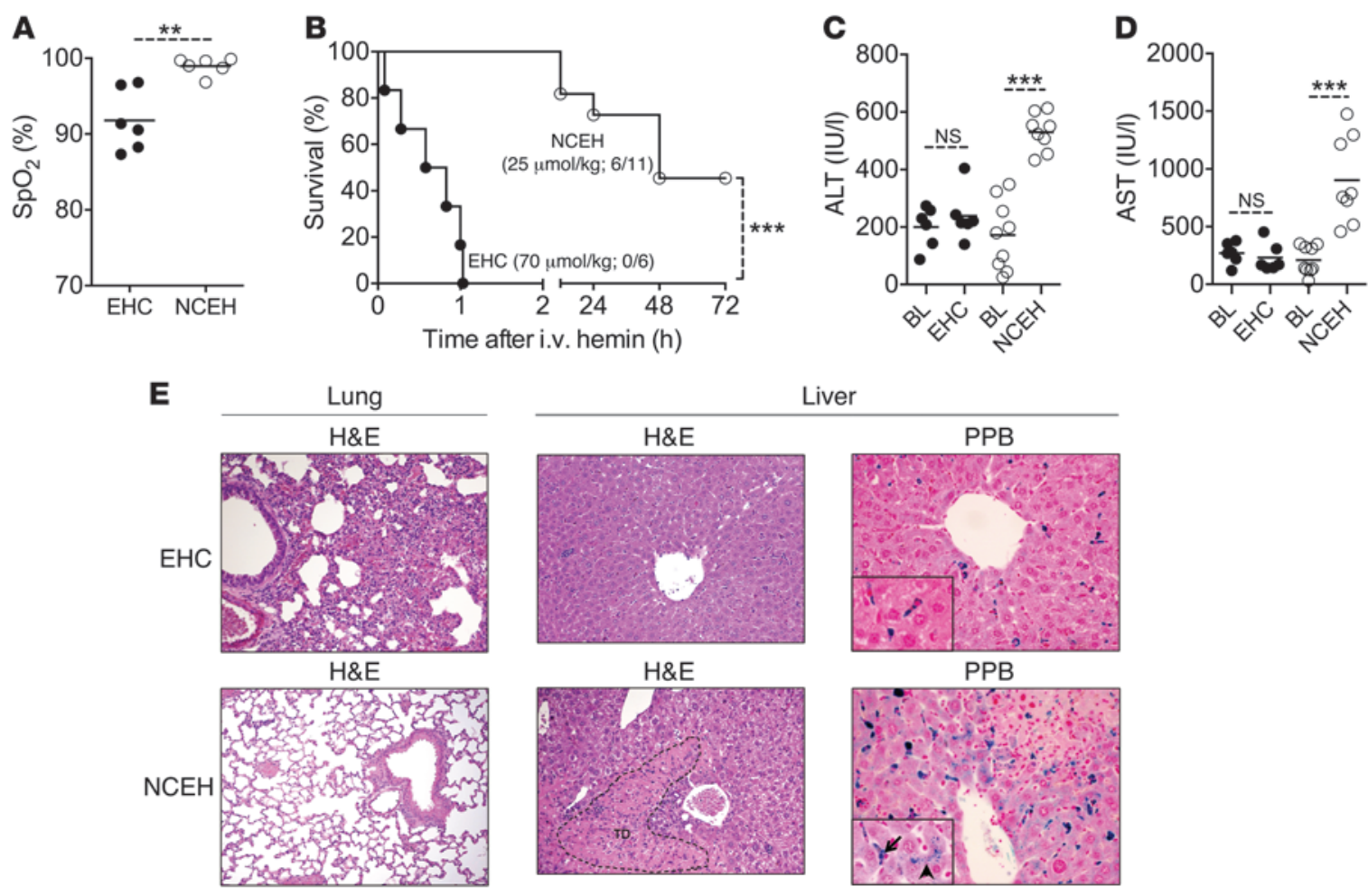

Liver

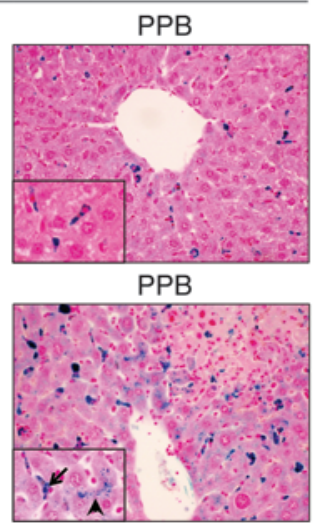

\section{Figure 5}

Extracellular and intracellular hemin species cause unique organ toxicities. (A-D) SS mice were given 70 and $25 \mu \mathrm{mol} / \mathrm{kg}$ hemin to induce EHC and $\mathrm{NCEH}$, respectively $(n=6-11)$. (A) $\mathrm{SpO}_{2}$ measured 20 minutes after induction. (B) Prognosis of SS mice. Death occurred within 2 hours in $100 \%$ of EHC mice and 12-72 hours later in 45\% of NCEH mice. (C and D) Plasma concentration of (C) ALT and (D) AST, determined at baseline and either 20 minutes $(\mathrm{EHC})$ or 24 hours (NCEH) after hemin challenge. (E) Representative H\&E-stained sections of postmortem lung and liver in SS mice with EHC and NCEH and Perl's Prussian blue (PPB) staining of the liver sections. Note the region of tissue damage (TD) likely caused by apoptosis and necrosis in the NCEH liver. Distribution of iron in Kupffer cells (arrow) and hepatocytes (arrowhead) was unique, with diffuse cytoplasmic staining in the hepatocytes. Original magnification, $\times 100(\mathrm{H} \& \mathrm{E}) ; \times 200$ (Perls); $\times 400$ (insets). ${ }^{* \star} P<0.01,{ }^{* \star *} P<0.001$.

vention, and treatment of ACS. First, we identified an autoamplification of extracellular hemin phenomenon in SCD. Second, we found that the hemin amplification was associated with ALI development and sudden death in mouse models of SCD. PFH was identified as the trigger, and low plasma $\mathrm{Hx}$ as the risk factor, for these sequelae. Third, TLR4 expressed in the vessel wall was found to be essential for the pathogenesis of this murine model of ALI. Finally, we demonstrated therapeutic as well as prophylactic roles for targeting the acute adverse effects of $\mathrm{PFH}$ with Hx and by TLR4 blockade. Thus, a vascular inflammatory response to excess extracellular hemin may play a central role in the pathogenesis of ACS.

SCD patients have raised plasma hemin concomitant with low Hx level $(39,40)$; however, the clinical significance of this interrelated anomaly had not previously been defined. Indirect evidence from clinical studies suggests that alterations in hemin catabolism contribute to the development of ACS. In a candidate gene study of 945 children in the silent infarct transfusion trial, a polymorphism in the HMOX-1 gene (which enhances expression of HO-1, the rate-limiting hemin degradation enzyme) was associated with lower rates of ACS incidence (24). More recently, using multivariable regression analysis, we found that in children with SCD, higher baseline PFH is associated with increased odds of ACS $(P=0.016$; odds ratio, 2.56 ; confidence interval, 1.19-5.47; ref. 41). These studies provide important clinical relevancy to our present findings that free hemin in the intravascular space directly caused lethal ALI, reminiscent of ACS, in 2 different mouse strains of SCD (Figures 1 and 2).

Acute hemolysis involving the loss of a large concentration of $\mathrm{Hb}$ (mean, 0.7-3.6 g/dl) preceding ACS is well documented in humans $(2,5-9,15)$, and we observed a similar phenomenon in mice. In the Cooperative Study of Sickle Cell Disease, in which there were 1,722 episodes of ACS in 939 patients, severe acute hemolysis that potentially increased extracellular $\mathrm{Hb}$ by $3.6 \mathrm{~g} / \mathrm{dl}$ (equivalent to $\sim 2.23 \mathrm{mM}$ hemin) was the only predictor of sudden death (15). Elevated LDH levels during ACS indicate that the hemolysis preceding this condition is largely intravascular (6), although not all the liberated $\mathrm{Hb}$ may become converted to hemin. Nonetheless, when we gave less than $20 \%$ of the hemin concentration associated with sudden death in the aforementioned human trial (i.e., $0.43 \mathrm{mM}$ ) to the SS mice in this study, $70 \%$ developed lethal ALI. This result suggests that the amount of hemin we used to trigger the ACS-like disease in SS mice is clinically reasonable.

Sickle erythrocytes trapped in vasoocclusions with reduced flow, shielded from plasma scavengers, and undergoing acute lysis are most likely the major sources of acute elevation in local extracellular hemin concentrations in patients. Thus, it may be challenging to directly determine the concentration of PFH that triggers ACS in patients. Our recent study suggests a high- 

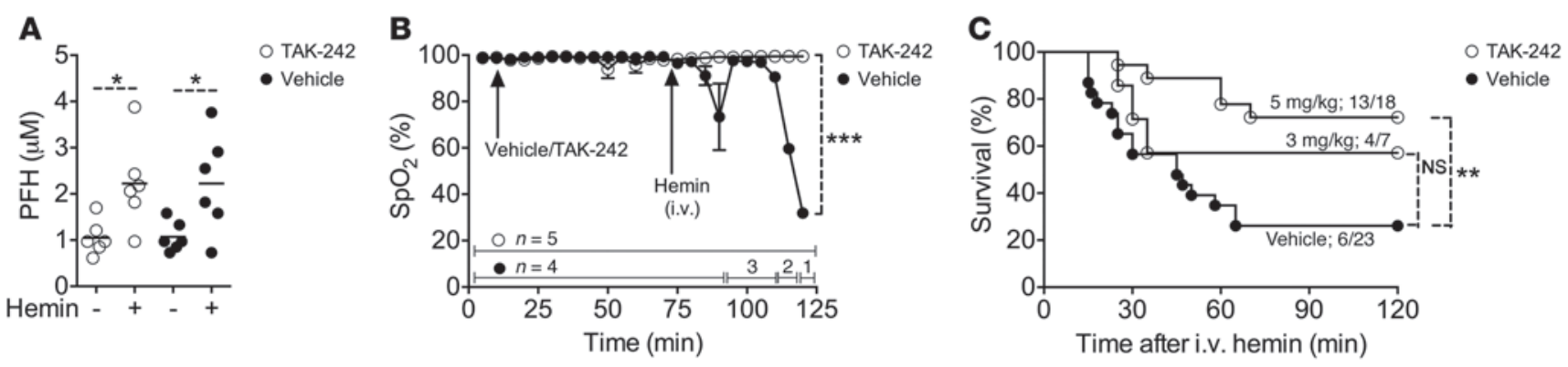

D

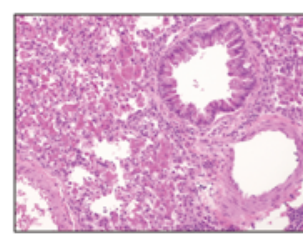

Vehicle

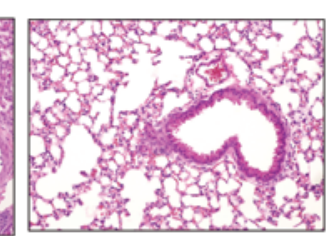

TAK-242

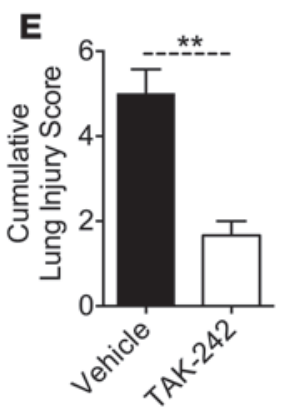

\section{Figure 6}

TAK-242 blocks ALI development in SS mice with EHC. (A) PFH in SS mice previously given i.v. injection of TAK-242 (5 mg/kg) or vehicle (intralipid; $50 \mu \mathrm{l}$ ) followed by hemin challenge. (B) Lung function in 9 hemin-challenged SS mice pretreated with TAK-242 $(n=5)$ or vehicle $(n=4)$. The number of surviving animals at each time point is indicated. (C) Survival of hemin-challenged SS mice pretreated with TAK-242 or vehicle. (D) Representative H\&E-stained lung sections of hemin-challenged SS mice pretreated with vehicle or $5 \mathrm{mg} / \mathrm{kg}$ TAK-242. Original magnification, $\times 100$. (E) Cumulative lung injury score in each group in $\mathbf{D}$. Data are mean $\pm \operatorname{SEM}(n=3) .{ }^{\star} P<0.05,{ }^{\star \star} P<0.01,{ }^{\star \star \star} P<0.001$.

er threshold of PFH may be required. The PFH in children with SCD at steady-state ranges $0.74-4.78 \mu \mathrm{M}(41)$. The mean value of that cohort $(1.59 \pm 0.09 \mu \mathrm{M} ; n=79)$ is significantly higher than the mean value for SS mice in the present study $(1.20 \pm 0.08 \mu \mathrm{M}$; range, $0.61-2.92 \mu \mathrm{M} ; n=38 ; P<0.01)$. One potential explanation for this difference is that, in common with other primates, human albumin forms a stable complex with hemin, unlike albumin from rodents (42). Indeed, the level of methemalbumin in the plasma of SCD patients is markedly elevated (43), highlighting the additional buffering of hemin in humans that is not available in mice. Albumin and other plasma proteins ultimately transfer hemin to $\mathrm{Hx}$ for delivery to the liver, the hemin/Hx complex is internalized, and hemin is degraded by HO-1. This catabolism occurs at an extremely rapid rate in SCD patients (40). Consequently, the Hx concentration in human SCD plasma is very low $(39,40)$, which we have previously confirmed $(0.24 \pm 0.02 \mathrm{mg} / \mathrm{ml}$, or $4.0 \pm 0.33 \mu \mathrm{M} ; n=81$; ref. 41$)$. In the present study, we demonstrated that SS mouse plasma had a similarly low level of $\mathrm{Hx}$ $(0.15 \pm 0.01 \mathrm{mg} / \mathrm{ml}$, or $2.5 \pm 0.16 \mu \mathrm{M} ; n=78)$ that was inadequate to counter a clinically feasible elevation in extracellular hemin that ultimately resulted in lethal ALI.

While our model recapitulates the key clinical features of human ACS defined by the National Acute Chest Syndrome Study Group (5), these features are not found in existing animal models of sickle-lung injury based on infection (10), hypoxia, and hypoxia/ reoxygenation $(14,35,44)$. Therefore, we believe our model represents a major breakthrough in this field. However, like many other animal models of ALI, it is potentially limited by the firstpass effect. Several evidentiary examples from our study mitigate this concern. The most compelling was the successful treatment of SS mice with rhHx several minutes after receiving a hemin bolus.
This recovery can be explained by the sequestration of a residual of the hemin bolus, or more likely endogenous hemin released by the ensuing EHC. Ironically, the SS mice in our study had 10-fold higher concentrations of plasma HO-1 (data not shown), which suggests they were more poised than the control mice to rapidly degrade the hemin bolus in the systemic circulation as well as in the liver, where expression of this enzyme is also upregulated in $\operatorname{SCD}(45,46)$. Our data suggest that it was the Hx in the systemic circulation, and not hepatic metabolism, that greatly reduced the potency of the hemin bolus to cause lung injury in SS mice.

Importantly, we excluded LPS, a potential contaminant of commercial preparations of hemin, as the source of ALI in our model. In addition, key features of ALI are substantially different for the hemin model described here and for LPS (47). However, there are similarities with other ALI models characterized by rapid hypoxemia and sudden lethality $(48,49)$. Because of the high concentration of TPH required to induce it in nonsickle mice, the hemin ALI may be unique to SCD, with in vivo amplification of hemin playing a potentially central role. In addition, free hemin modulates the expression of COMMD7 in cultured pulmonary endothelial cells (50). This gene is highly expressed in the lung (51) and interacts with NF- KB signaling $(51,52)$, and a recent study found that it contains a polymorphism with an array-wide significant association with ACS $\left(P=4.1 \times 10^{-7}\right)$ in the Cooperative Study of Sickle Cell Disease cohort (50). Although more work is needed to clarify the role of the endothelium in our model, these results, together with our present findings using chimeric SS mice, add further evidence in support of a role for hemin signaling in the pulmonary endothelium in ACS.

One of the most fascinating findings of this study is the discovery of extracellular hemin autoamplification. This phenomenon 

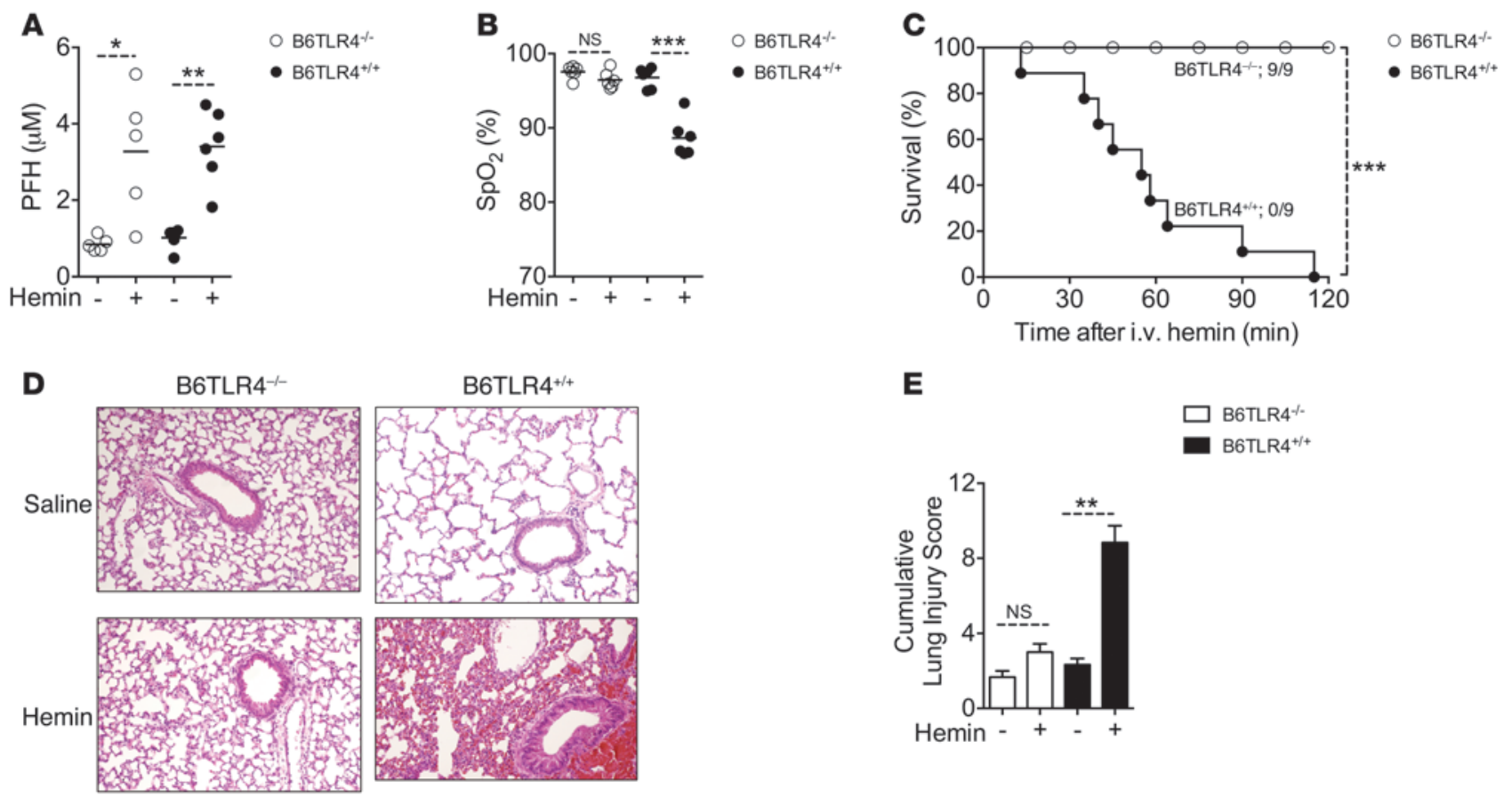

E

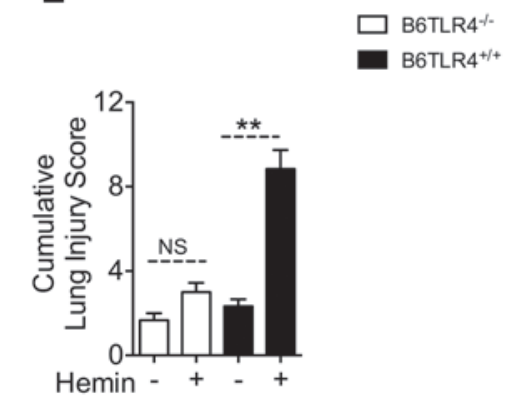

\section{Figure 7}

TLR4 is required for hemin-induced ALI. (A) Nonanemic B6TLR4 ${ }^{-/-}$and B6TLR4 $4^{+/+}$mice $(n=5-6)$ were injected with $210 \mu \mathrm{mol} / \mathrm{kg}$ hemin to raise $\mathrm{PFH}$ to levels comparable to those of SS mice with EHC. (B) Lung function, determined by $\mathrm{SpO}_{2}$. (C) Survival rate showing no lethality in heminchallenged B6TLR4 ${ }^{-/-}$mice. (D) Representative H\&E-stained lung sections of B6TLR4 ${ }^{-/-}$and B6TLR4 $4^{+/}$mice challenged with saline or hemin. Original magnification, $\times 100$. (E) Cumulative lung injury score. Data are mean $\pm \operatorname{SEM}(n=6) .{ }^{*} P<0.05,{ }^{* \star} P<0.01,{ }^{\star \star \star} P<0.001$.

may help to explain a paradox reported nearly 50 years ago: that the plasma of SCD patients contains inexplicably higher concentrations of hemin discordant with the corresponding levels of plasma $\mathrm{Hb}(39)$. It is too early to know exactly what controls this process; however, several clues emerged from our present findings. Whereas oxidation of intracellular $\mathrm{Hb}$ by extracellular hemin occurred at a faster rate in SS than control mice, other oxidants do not show this differential effect for sickle-cell $\mathrm{Hb}$ (HbS) in vitro (53). The newly formed metHbS persisted probably because of the low activity of metHb reductase in sickle erythrocytes (54). In addition, hemolysis in sickle mice occurred more rapidly than in wild-type mouse erythrocytes exposed to similar concentrations of free hemin ex vivo $(55,56)$. Collectively, these observations provide a framework for further research to delineate the factors that influence $\mathrm{EHC}$ and to examine its role in end-organ damage in SCD.
The current state-of-the-art management of ACS is entirely supportive, involving interventions such as supplemental oxygen, empiric antibiotics, and blood transfusions (57). These therapies are not targeted or standardized; furthermore, they are associated with multiple risks. Consequently, a major clinical objective in SCD is to prevent ACS, using various disease-modifying approaches, particularly in patients with repeated episodes and in those hospitalized with VOC. Thus, a major strength of our study is that it may help to refine this prophylactic strategy by targeting specific molecules, such as hemin, and other pathways directly involved in causing lung injury. A targeted approach may also be effective therapeutically, as shown here for SS mice with respiratory distress that were saved from respiratory failure using rhHx. We have also identified TLR4 antagonists as potential agents for drug repurposing in SCD, despite their recent setbacks in sepsis trials (58-60). There is an emerging consensus that these drugs perform poorly in sepsis trials because it may be too late to block

\section{Table 2}

Effect of EHC in wild-type and chimeric SS mice

\begin{tabular}{|c|c|c|c|c|c|c|}
\hline & \multicolumn{2}{|c|}{ SSTLR4+/+ } & \multicolumn{2}{|c|}{ SSNH/TLR4-/- } & \multicolumn{2}{|c|}{ SSWT } \\
\hline & Baseline & EHC & Baseline & EHC & Baseline & EHC \\
\hline metHb (\%) & $3.23 \pm 0.54$ & $18.9 \pm 1.01^{A}$ & $2.86 \pm 0.4$ & $17.23 \pm 0.52^{\mathrm{A}}$ & $3.5 \pm 0.37$ & $17.67 \pm 0.53^{A}$ \\
\hline Total Hb (g/dl) & $7.6 \pm 0.3$ & $6.9 \pm 0.08$ & $8.33 \pm 0.57$ & $7.16 \pm 0.18$ & $7.13 \pm 0.43$ & $6.03 \pm 0.54$ \\
\hline Plasma Hb (g/dl) & $0.11 \pm 0.01$ & $0.81 \pm 0.04^{B}$ & $0.11 \pm 0.008$ & $1.97 \pm 0.54^{B}$ & $0.07 \pm 0.01$ & $1.67 \pm 0.1^{\mathrm{A}}$ \\
\hline $\mathrm{TPH}(\mu \mathrm{M})$ & $66.99 \pm 6.68$ & $985 \pm 248^{A}$ & $71.14 \pm 5.53$ & $1,232 \pm 339 A$ & $48.29 \pm 8.9$ & $1,043 \pm 85^{A}$ \\
\hline PFH ( $\mu \mathrm{M})$ & $1.58 \pm 0.23$ & $3.7 \pm 0.45^{B}$ & $1.24 \pm 0.04$ & $2.8 \pm 0.2^{\mathrm{C}}$ & $1.44 \pm 0.33$ & $3.23 \pm 0.4 \mathrm{~B}$ \\
\hline
\end{tabular}

Values are mean $\pm \operatorname{SEM}(n=3) .{ }^{A} P<0.001,{ }^{\mathrm{B}} P<0.05,{ }^{C} P<0.01$ vs. baseline. 
A
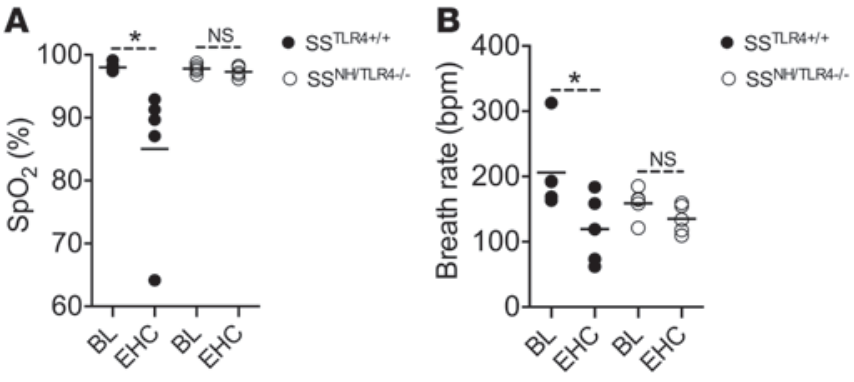

D

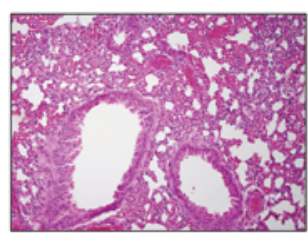

SS TLA4N+ $^{\text {Th }}$

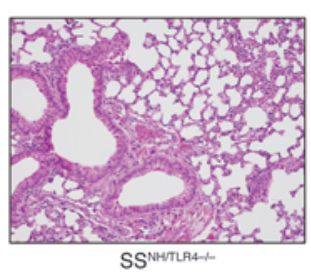

E

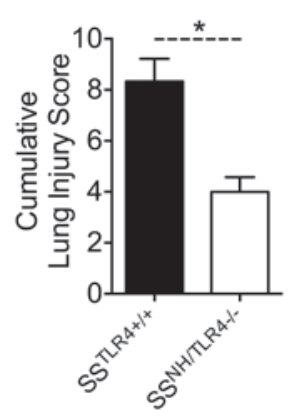

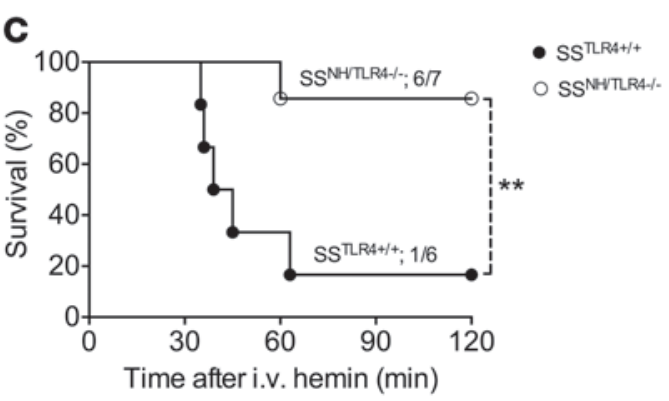

F

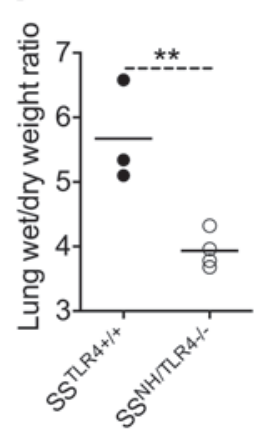

Figure 8

TLR4 mediates ALI in chimeric SS mice with EHC. (A and B) Lung function, determined by $(\mathbf{A}) \mathrm{SpO}_{2}$ and (B) breath rate, in SS ${ }^{\mathrm{TLR} 4+/+}$ and SS $\mathrm{BH}^{\mathrm{NTLR}-1-}$

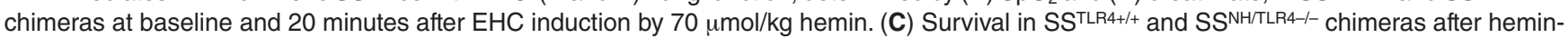
induced EHC. (D) Representative H\&E-stained lung sections. Original magnification, $\times 100$. (E) Cumulative lung injury score. Data are mean \pm SEM $(n=3)$. (F) Lung wet/dry weight ratios showed lung edema in SS ${ }^{\mathrm{TLR} 4+/+}$, but not SS ${ }^{\mathrm{NH} / \mathrm{TLR} 4-/-}$, chimeras $(n=3-4) .{ }^{\star} P<0.05,{ }^{* *} P<0.01$.

TLR4 once septic shock is already underway. Although TAK-242 was not effective in SS mice with established respiratory distress, it prevented respiratory failure when administered at the onset of hemolytic crisis. Importantly, a majority of SCD patients (up to $70 \%$ in one study; ref. 6) who develop ACS present initially with well-defined antecedent events that are interceded by acute hemolysis. Thus, acute prophylaxis using TLR4 blockade may be an attractive strategy to alter the course of ACS clinically. In conclusion, we offer a mechanism to explain the pathogenesis of ACS and a rational strategy that may help to develop targeted therapies for this life-threatening condition.

\section{Methods}

Reagents and drugs. Hemin [Fe(III)PPIX; Frontier Scientific Inc. and Sigma-Aldrich] was prepared by dissolving in $0.25 \mathrm{M} \mathrm{NaOH}, \mathrm{pH}$ was neutralized to 7.4 with $\mathrm{HCl}$, and the solution was adjusted to required concentration with PBS, filter sterilized, and used immediately. Na-PPIX and Fe(III) MPIX (Frontier Scientific Inc.) were dissolved and used as described for hemin. Endotoxin contamination in porphyrin preparations was screened using the Toxin Sensor Chromogenic LAL Endotoxin Assay Kit (GenScript). rhHx (>90\% purity) was custom prepared and lyophilized in $25 \mathrm{mM}$ MES, $0.15 \mathrm{M} \mathrm{NaCl}$ buffer (R\&D Systems). Human IgG protein was procured from Abcam. TAK-242, a small-molecule inhibitor of TLR4 signaling, was purchased from Invivogen and dissolved in intralipid (Sigma-Aldrich). Polymyxin B and phenylhydrazine were obtained from Sigma-Aldrich.

Mice and procedures. We have established colonies of both the Townes (SS; ref. 61) and Berkeley (62) sickle mice in our laboratory, as previously reported (46). Mouse genotypes were confirmed either by PCR or $\mathrm{Hb}$ gel electrophoresis. The following mice were obtained from The Jackson Laboratory: B6TLR4+/+ (wild-type C57BL/6J; stock no. 000664), B6TLR4-/congenics (B6.B10ScN-Tlr4lps-del/JthJ, with a small deletion in the mouse
Tlr4 gene; stock no. 007227), wild-type C3H/HeOuJ (stock no. 000635), and $\mathrm{C} 3 \mathrm{H} / \mathrm{HeJ}$ congenics, with a point mutation in the mouse $\mathrm{Tl} 4$ gene (stock no. 000659). Mice were injected with (a) freshly prepared solutions of hemin, hemin analogs, and saline (i.v.); (b) rhHx (i.v.; $1 \mathrm{mg} / \mathrm{mouse}$ ), for which the lyophilization buffer $(25 \mathrm{mM} \mathrm{MES}, 0.15 \mathrm{M} \mathrm{NaCl})$ for the preparation of rhHx was used as vehicle; (c) phenylhydrazine (i.p.; $100 \mathrm{mg} / \mathrm{kg}$ ); (d) TAK-242 or intralipid vehicle (i.v.); and (e) aqueous solution of Polymyxin B as previously described (63). For hypoxia/reoxygenation experiments, SS mice housed in their standard cages were transferred into a hypoxia chamber (BioSpherix) fitted with a ProOx 110 gas controller (BioSpherix) in line with a high pressure double gauge mixed gas primary nitrogen regulator fitted onto a vaporized nitrogen source. Mice were exposed to $8 \%$ oxygen for 3 hours and returned to room air (reoxygenation) for 4 hours as previously described (35). Mice were phlebotomized by retro-orbital bleeding using a capillary tube internally coated with heparin/EDTA anticoagulant.

Whole blood co-oximetry. Total $\mathrm{Hb}$ concentration and percent metHb were measured in venous whole blood using a portable CO-oximeter (AVOXImeter 4000 ; ITC) as described previously (64). The device measures the level of different $\mathrm{Hb}$ parameters using novel optics and multiple wavelengths (65). Plasma $\mathrm{Hb}$ concentration was determined by colorimetric method using a Quantichrome Hb assay kit (Bioassay Systems).

Plasma biomarker analysis. Freshly collected EDTA anticoagulated blood samples were centrifuged at $1,200 \mathrm{~g}, 4^{\circ} \mathrm{C}$, for 10 minutes to collect plasma. In some experiments, this unfractionated plasma was subjected to a second spin through a Microcon YM-3 column (Millipore) at $20,000 \mathrm{~g}, 4^{\circ} \mathrm{C}$, for 2 hours to prepare a protein-depleted plasma fraction devoid of molecules of MW $>3 \mathrm{kDa}$. Hemin content in the unfractionated and protein-depleted plasma was quantified to obtain TPH and PFH, respectively, using a colorimetric assay kit (Bioassay Systems) as described previously $(64,66)$. ELISA 
A

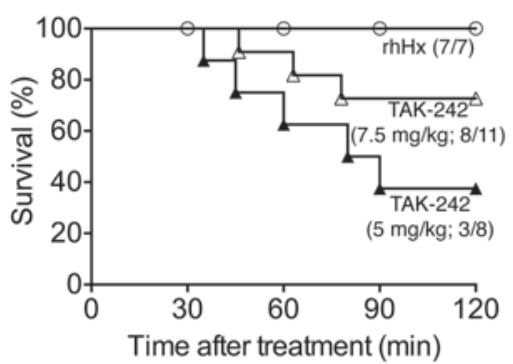

B

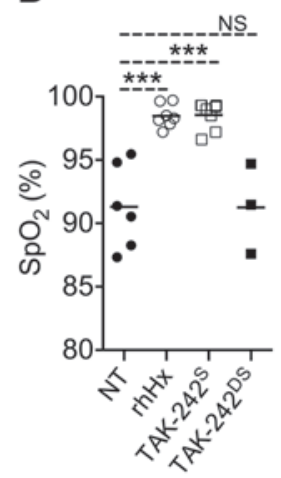

C

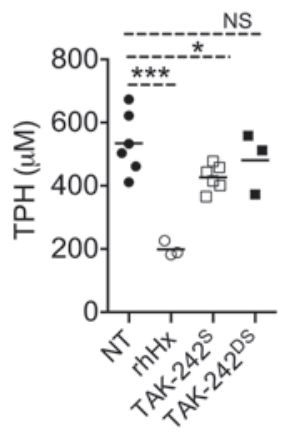

D

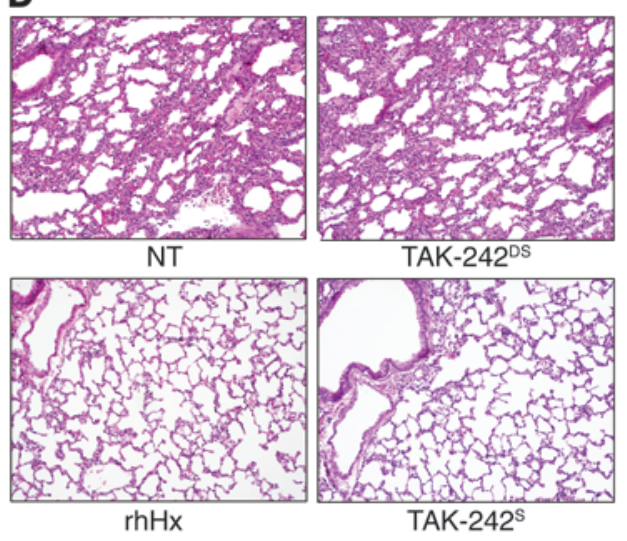

E

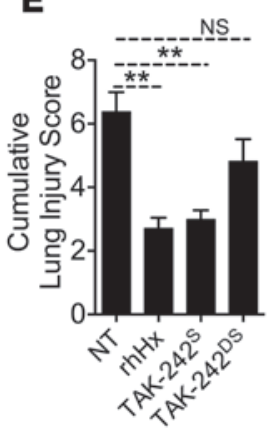

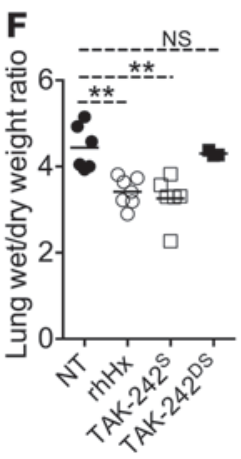

G
H

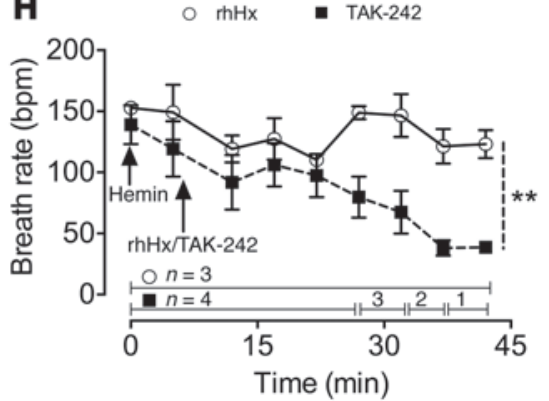

Figure 9

$\mathrm{Hx}$ and TAK-242 treatment prevents respiratory failure in SS mice. (A) Survival of SS mice treated as indicated at the onset of hemolytic crisis induced with $35 \mu \mathrm{mol} / \mathrm{kg}$ hemin. (B) $\mathrm{SpO}_{2}$, determined 20 minutes after initiation of therapy. Note the lower mean $\mathrm{SpO}_{2}$ in the nontreated (NT) group and 3 of the mice given $7.5 \mathrm{mg} / \mathrm{kg}$ TAK-242. TAK-242S , survived; TAK-242 ${ }^{\mathrm{DS}}$, did not survive. (C) TPH 30 minutes after treatment. Values for rhHx-treated mice were significantly reduced compared with nontreated and TAK-242 groups. (D) Representative H\&E-stained lung sections of organs harvested after the end of the experiment ( $\mathrm{rhHx}$ and TAK-242S) or immediately after death (nontreated and TAK-242DS). Original magnification, $\times 100$. (E) Cumulative lung injury score. Data are mean \pm SEM $(n=3)$. (F) Lung wet/dry weight ratio $(n=3-7)$. (G) $\mathrm{SpO}_{2}$ and $(\mathbf{H})$ breath rate of SS mice treated several minutes after the onset of hemolytic crisis and after showing evidence of respiratory distress. The number of surviving animals at each time point is indicated. ${ }^{*} P<0.05,{ }^{\star *} P<0.01,{ }^{\star \star *} P<0.001$.

with specific commercial kits (Kamiya Biomedical Co.) was used to measure $\mathrm{Hx}$ and haptoglobin concentration according to the manufacturer's instructions. Enzyme activity of ALT and AST was measured using a colorimetric method (Teco Diagnostics) according to the manufacturer's instructions.

Pulse-oximetry. The MouseOx pulse-oximeter (Starr Life Sciences) was used (31) to measure real-time $\mathrm{SpO}_{2}$ (percentage of functional arterial $\mathrm{Hb}$ ) and breath rate per minute in awake conditions. Hairs from the collar region (back of the neck) were removed using a depilatory agent 1 day before actual measurement. A disposable sensory collar clip attached to the pulse-oximeter was placed on the hairless area, and measurements were initiated through MouseOx software (version 6.3; provided by the manufacturer) when data displays were without error codes. Recorded values were pooled for each consecutive 5-minute interval, and mean values were then used for analysis where continuous screening was presented.

Blood gas analysis. Animals were anesthetized using recommended doses of ketamine and xylazine given i.p. A left ventricular heart puncture was performed with a heparinized syringe to collect the arterial blood. $\mathrm{PaO}_{2}$ was measured, and $\mathrm{SO}_{2}$ was determined immediately from the whole blood using a VitalPath blood gas and electrolyte analyzer (Heska).

Gravimetric analysis of lung edema. The whole lungs were harvested from mice, either immediately after death or 2 hours after hemin injection, and weighed using an isometric transducer (Harvard Apparatus). Lungs were then dried in an oven at $80^{\circ} \mathrm{C}$ containing desiccant crystals for 24 hours, dry weight was determined, and lung wet/dry weight ratios were calculated (67). Bone marrow transplantation. B6TLR $4^{+/+}$and B6TLR4 ${ }^{-/-}$mice were maintained on acidified drinking water for 7 days and subjected to 2 doses of 6-Gy irradiation given 4 hours apart. Irradiated mice were transplanted with $5 \times 10^{6}$ whole bone marrow cells harvested from SS mouse donors. The transplanted SS ${ }^{\mathrm{TLR} 4+/+}$ and SS ${ }^{\mathrm{NH} / \mathrm{TLR} 4-/-}$ chimeras were maintained on medicated water $(0.5 \mathrm{mg} / \mathrm{ml}$ neomycin, $0.0125 \mathrm{mg} / \mathrm{ml}$ polymyxin B) for 1 week. Blood samples were collected from transplanted mice 8 weeks after transplant for complete blood count (CBC) using a HemaTrue hematology analyzer (Heska) and to assess engraftment of donor bone marrow and reticulocyte count using flow cytometry.

Histopathology. Lungs and livers were harvested immediately after death, or removed at the end of specific experiments (usually 2 hours), and fixed uniformly with $10 \%$ buffered formalin. Tissue sections were stained with H\&E and examined using an Olympus AX70 microscope, and images were recorded with an Olympus U-CMAD3 DP70 camera and Olympus DP70/DP30 BW software (version 02.0201.147). Histopathological analysis was performed by a modified extensive scoring system, as previously described $(35,68,69) .4$ criteria were used to score lung injury: edema, hemorrhage, alveolar wall thickening and vascular congestion. Sections were scored as follows: 0 , absent; 1 , mild; 2 , moderate; 
3 , severe; 4 , very severe. Individual scores were tabulated from the mean score from 6 random focal areas (magnification, $\times 100$ ) to obtain an overall score ranging $0-16$. The mean injury score was determined for lungs from each animal in an experimental group $(n=3-6)$ to generate a cumulative lung injury score. In addition to $\mathrm{H} \& \mathrm{E}$, liver tissue sections were stained with Perls' Prussian blue and counterstained with fast-red to detect intracellular iron.

Statistics. To analyze statistical significance, 2-tailed unpaired Student's $t$ test or 1-way ANOVA was used as appropriate. Survival rates were compared by log-rank (Mantel-Cox) test. GraphPad Prism 5 software was used for all statistical analyses. A $P$ value less than 0.05 was considered significant.

Study approval. All mice studies were approved by IACUC of Emory University (protocol no. DAR-2001829-070813).

\section{Acknowledgments}

This work was supported by research funding from the NHLBI (grants K02HL088026, 1U01HL117721, and R01HL106192) and the American Heart Association (grant GRNT7320008).

Received for publication May 7, 2012, and accepted in revised form August 1, 2013.

Address correspondence to: Solomon F. Ofori-Acquah, Aflac Cancer and Blood Disorders Center, Department of Pediatrics, Emory University School of Medicine, 2015 Uppergate Drive, Atlanta, Georgia 30322, USA. Phone: 404.727.2293; Fax: 404.727.4455; E-mail: soforia@emory.edu.
1. McCavit TL, Lin H, Zhang S, Ahn C, Quinn CT, Flores G. Hospital volume, hospital teaching status, patient socioeconomic status, and outcomes in patients hospitalized with sickle cell disease. Am J Hematol. 2011;86(4):377-380.

2. Castro O, et al. The acute chest syndrome in sickle cell disease: incidence and risk factors. The Cooperative Study of Sickle Cell Disease. Blood. 1994; 84(2):643-649.

3. Gladwin MT, Vichinsky E. Pulmonary complications of sickle cell disease. $N$ Engl J Med. 2008; 359(21):2254-2265.

4. Platt OS, et al. Mortality in sickle cell disease. Life expectancy and risk factors for early death. NEnglJ Med. 1994;330(23):1639-1644.

5. Vichinsky EP, et al. Causes and outcomes of the acute chest syndrome in sickle cell disease. National Acute Chest Syndrome Study Group. N Engl J Med. 2000;342(25):1855-1865.

6. Maitre B, et al. Acute chest syndrome in adults with sickle cell disease. Chest. 2000;117(5):1386-1392.

7. Davies SC, Luce PJ, Win AA, Riordan JF, Brozovic M. Acute chest syndrome in sickle-cell disease. Lancet. 1984;1(8367):36-38.

8. Gladwin MT, Schechter AN, Shelhamer JH, Ognibene FP. The acute chest syndrome in sickle cell disease. Possible role of nitric oxide in its pathophysiology and treatment. Am J Respir Crit Care Med. 1999;159(5 pt 1):1368-1376.

9. Sprinkle RH, Cole T, Smith S, Buchanan GR. Acute chest syndrome in children with sickle cell disease. A retrospective analysis of 100 hospitalized cases. Am J Pediatr Hematol Oncol. 1986;8(2):105-110.

10. Holtzclaw JD, Jack D, Aguayo SM, Eckman JR, Roman J, Hsu LL. Enhanced pulmonary and systemic response to endotoxin in transgenic sickle mice. Am J Respir Crit Care Med. 2004;169(6):687-695.

11. Martinez-Ruiz R, Montero-Huerta P, Hromi J, Head CA. Inhaled nitric oxide improves survival rates during hypoxia in a sickle cell (SAD) mouse model. Anesthesiology. 2001;94(6):1113-1118.

12. Pritchard KA, et al. Hypoxia-induced acute lung injury in murine models of sickle cell disease. $A m J$ Physiol Lung Cell Mol Physiol. 2004;286(4):L705-L714.

13. Kaul DK, Hebbel RP. Hypoxia/reoxygenation causes inflammatory response in transgenic sickle mice but not in normal mice. J Clin Invest. 2000; 106(3):411-420.

14. de Franceschi L, et al. Inhaled nitric oxide protects transgenic SAD mice from sickle cell disease-specific lung injury induced by hypoxia/reoxygenation. Blood. 2003;102(3):1087-1096.

15. Vichinsky EP, Styles LA, Colangelo LH, Wright EC, Castro O, Nickerson B. Acute chest syndrome in sickle cell disease: clinical presentation and course. Cooperative Study of Sickle Cell Disease. Blood. 1997; 89(5):1787-1792.

16. van Agtmael MA, Cheng JD, Nossent HC. Acute chest syndrome in adult Afro-Caribbean patients with sickle cell disease. Analysis of 81 episodes among 53 patients. Arch Intern Med. 1994; 154(5):557-561.

17. Wagener FA, et al. Heme is a potent inducer of inflammation in mice and is counteracted by heme oxygenase. Blood. 2001;98(6):1802-1811.

18. Figueiredo RT, et al. Characterization of heme as activator of Toll-like receptor 4. J Biol Chem. 2007; 282(28):20221-20229.

19. Hebbel RP, Morgan WT, Eaton JW, Hedlund BE. Accelerated autoxidation and heme loss due to instability of sickle hemoglobin. Proc Natl Acad Sci US A. 1988;85(1):237-241.

20. Jeney V, et al. Pro-oxidant and cytotoxic effects of circulating heme. Blood. 2002;100(3):879-887.

21. Umbreit J. Methemoglobin--it's not just blue: a concise review. Am J Hematol. 2007;82(2):134-144.

22. Hebbel RP. Reconstructing sickle cell disease: a databased analysis of the "hyperhemolysis paradigm" for pulmonary hypertension from the perspective of evidence-based medicine. Am J Hematol. 2011; 86(2):123-154.

23. Liu SC, Zhai S, Palek J. Detection of hemin release during hemoglobin S denaturation. Blood. 1988; 71(6):1755-1758.

24. Bean CJ, et al. Heme oxygenase-1 gene promoter polymorphism is associated with reduced incidence of acute chest syndrome among children with sickle cell disease. Blood. 2012;120(18):3822-3828.

25 . Klings ES, et al. Increased F2 isoprostanes in the acute chest syndrome of sickle cell disease as a marker of oxidative stress. Am J Respir Crit Care Med. 2001; 164(7):1248-1252.

26. Belcher JD, Mahaseth H, Welch TE, Otterbein LE, Hebbel RP, Vercellotti GM. Heme oxygenase-1 is a modulator of inflammation and vaso-occlusion in transgenic sickle mice. J Clin Invest. 2006; 116(3):808-816.

27. Vinchi F, Gastaldi S, Silengo L, Altruda F, Tolosano E. Hemopexin prevents endothelial damage and liver congestion in a mouse model of heme overload. Am J Pathol. 2008;173(1):289-299.

28. Larsen R, et al. A central role for free heme in the pathogenesis of severe sepsis. Sci Transl Med. 2010; 2(51):51ra71.

29. Bernini JC, Rogers ZR, Sandler ES, Reisch JS, Quinn CT, Buchanan GR. Beneficial effect of intravenous dexamethasone in children with mild to moderately severe acute chest syndrome complicating sickle cell disease. Blood. 1998;92(9):3082-3089.

30. Sidwell RW, et al. Utilization of pulse oximetry for the study of the inhibitory effects of antiviral agents on influenza virus in mice. Antimicrob Agents Chemother. 1992;36(2):473-476.

31. Verhoeven D, Teijaro JR, Farber DL. Pulse-oximetry accurately predicts lung pathology and the immune response during influenza infection. Virology. 2009;390(2):151-156.

32. Kaul DK, Fabry ME, Suzuka SM, Zhang X. Antisickling fetal hemoglobin reduces hypoxia-inducible factor-1alpha expression in normoxic sickle mice: microvascular implications. Am J Physiol Heart Circ Physiol. 2013;304(1):H42-H50.

33. Rodrigues SF, et al. Differential effects of chloral hydrate- and ketamine/xylazine-induced anesthesia by the s.c. route. Life Sci. 2006;79(17):1630-1637.

34. Schwarzkopf TM, Horn T, Lang D, Klein J. Blood gases and energy metabolites in mouse blood before and after cerebral ischemia: the effects of anesthetics. Exp Biol Med (Maywood). 2013;238(1):84-89.

35. Wallace KL, et al. NKT cells mediate pulmonary inflammation and dysfunction in murine sickle cell disease through production of IFN-gamma and CXCR3 chemokines. Blood. 2009;114(3):667-676.

36. Takashima K, et al. Analysis of binding site for the novel small-molecule TLR4 signal transduction inhibitor TAK-242 and its therapeutic effect on mouse sepsis model. Br J Pharmacol. 2009; 157(7):1250-1262.

37. Qureshi ST, et al. Endotoxin-tolerant mice have mutations in Toll-like receptor 4 (Tlr4). J Exp Med. 1999;189(4):615-625.

38. Sha T, Sunamoto M, Kitazaki T, Sato J, Ii M, Iizawa Y. Therapeutic effects of TAK-242, a novel selective Toll-like receptor 4 signal transduction inhibitor, in mouse endotoxin shock model. Eur J Pharmacol. 2007;571(2-3):231-239.

39. Muller-Eberhard U, Javid J, Liem HH, Hanstein A, Hanna M. Plasma concentrations of hemopexin, haptoglobin and heme in patients with various hemolytic diseases. Blood. 1968;32(5):811-815.

40. Wochner RD, Spilberg I, Iio A, Liem HH, MullerEberhard U. Hemopexin metabolism in sickle-cell disease, porphyrias and control subjects - effects of heme injection. NEnglJ Med. 1974;290(15):822-826.

41. Adisa OA, Hu Y, Ghosh S, Aryee D, Osunkwo I, Ofori-Acquah SF. Association between plasma free haem and incidence of vaso-occlusive episodes and acute chest syndrome in children with sickle cell disease. BrJ Haematol. 2013;162(5):702-705.

42. Bunn HF, Jandl JH. Exchange of heme among hemoglobins and between hemoglobin and albumin. J Biol Chem. 1968;243(3):465-475.

43. Hanson MS, et al. Methaemalbumin formation in sickle cell disease: effect on oxidative protein modification and HO-1 induction. Br J Haematol. 2011; 154(4):502-511.

44. Wallace KL, Linden J. Adenosine A2A receptors induced on iNKT and NK cells reduce pulmonary inflammation and injury in mice with sickle cell disease. Blood. 2010;116(23):5010-5020.

45. Nath KA, et al. Oxidative stress and induction of heme oxygenase- 1 in the kidney in sickle cell disease. Am J Pathol. 2001;158(3):893-903.

46. Ghosh S, et al. Global gene expression profiling of endothelium exposed to heme reveals an organspecific induction of cytoprotective enzymes in sickle cell disease. PLoS One. 2011;6(3):e18399.

47. Matute-Bello G, Frevert CW, Martin TR. Animal models of acute lung injury. Am J Physiol Lung Cell Mol Physiol. 2008;295(3):L379-L399. 
48. Looney MR, Su X, Van Ziffle JA, Lowell CA, Matthay MA. Neutrophils and their Fc gamma receptors are essential in a mouse model of transfusion-related acute lung injury. J Clin Invest. 2006; 116(6):1615-1623.

49. Looney MR, Nguyen JX, Hu Y, Van Ziffle JA, Lowell CA, Matthay MA. Platelet depletion and aspirin treatment protect mice in a two-event model of transfusion-related acute lung injury. J Clin Invest. 2009;119(11):3450-3461.

50. Galarneau G, et al. Gene-centric association study of acute chest syndrome and painful crisis in sickle cell disease patients. Blood. 2013;122(3):434-442.

51. Burstein E, et al. COMMD proteins, a novel family of structural and functional homologs of MURR1. J Biol Chem. 2005;280(23):22222-22232.

52. Zheng L, et al. ShRNA-targeted COMMD7 suppresses hepatocellular carcinoma growth. PLoS One. 2012;7(9):e45412.

53. Sheng K, Shariff M, Hebbel RP. Comparative oxidation of hemoglobins A and S. Blood. 1998; 91(9):3467-3470.

54. Zerez CR, Lachant NA, Tanaka KR. Impaired erythrocyte methemoglobin reduction in sickle cell disease: dependence of methemoglobin reduction on reduced nicotinamide adenine dinucleotide con- tent. Blood. 1990;76(5):1008-1014.

55. Chou AC, Fitch CD. Hemolysis of mouse erythrocytes by ferriprotoporphyrin IX and chloroquine. Chemotherapeutic implications. J Clin Invest. 1980; 66(4):856-858.

56. Chou AC, Fitch CD. Mechanism of hemolysis induced by ferriprotoporphyrin IX. J Clin Invest. 1981;68(3):672-677.

57. Desai PC, Ataga KI. The acute chest syndrome of sickle cell disease. Expert Opin Pharmacother. 2013; 14:991-999.

58. Rice TW, et al. A randomized, double-blind, placebo-controlled trial of TAK-242 for the treatment of severe sepsis. Crit Care Med. 2010;38(8):1685-1694.

59. Opal SM, et al. Effect of eritoran, an antagonist of MD2-TLR4, on mortality in patients with severe sepsis: the ACCESS randomized trial. JAMA. 2013; 309(11):1154-1162

60. Tse MT. Trial watch: Sepsis study failure highlights need for trial design rethink. Nat Rev Drug Discov. 2013;12(5):334.

61. Wu LC, Sun CW, Ryan TM, Pawlik KM, Ren J, Townes TM. Correction of sickle cell disease by homologous recombination in embryonic stem cells. Blood. 2006;108(4):1183-1188.

62. Paszty C, et al. Transgenic knockout mice with exclusively human sickle hemoglobin and sickle cell disease. Science. 1997;278(5339):876-878.

63. Rifkind D. Prevention by polymyxin B of endotoxin lethality in mice. J Bacteriol. 1967;93(4):1463-1464.

64. Pamplona A, et al. Heme oxygenase-1 and carbon monoxide suppress the pathogenesis of experimental cerebral malaria. Nat Med. 2007;13(6):703-710.

65 . Hemmi H, et al. The roles of two IkappaB kinaserelated kinases in lipopolysaccharide and double stranded RNA signaling and viral infection. $J$ Exp Med. 2004;199(12):1641-1650.

66. Seixas E, et al. Heme oxygenase-1 affords protection against noncerebral forms of severe malaria. Proc Natl Acad Sci U S A. 2009;106(37):15837-15842.

67. Ghosh S, Tan F, Ofori-Acquah SF. Spatiotemporal dysfunction of the vascular permeability barrier in transgenic mice with sickle cell disease. Anemia. 2012;2012:582018

68. Belperio JA, et al. Critical role for CXCR2 and CXCR2 ligands during the pathogenesis of ventilator-induced lung injury. J Clin Invest. 2002;110(11):1703-1716.

69. Imanaka H, Nishimura M, Miyano H, Uemura H, Yagihara T. Effect of synchronized intermittent mandatory ventilation on respiratory workload in infants after cardiac surgery. Anesthesiology. 2001; 95(4):881-888. 